\title{
Degeneration of the Golgi and neuronal loss in dorsal root ganglia in diabetic BioBreeding/Worcester rats
}

\author{
H. Kamiya $\cdot$ W. Zhang • A. A. F. Sima
}

Received: 23 May 2006 / Accepted: 30 May 2006 / Published online: 20 September 2006

(C) Springer-Verlag 2006

\begin{abstract}
Aims/hypothesis The aim of this study was to evaluate the nature and extent of neuronal loss in dorsal root ganglia (DRG) in diabetic polyneuropathy.

Materials and methods We examined 10-month diabetic BioBreeding/Worcester (BB/Wor) rats with respect to DRG ultrastructure and morphometry, sural nerve morphometry, pro- and anti-apoptotic proteins, the expression of neurotrophic factors and their receptors, and sensory nerve functions.

Results In diabetic rats, DRG neurons decreased to $73 \%$ of normal, owing to loss of substance $\mathrm{P}$ and calcitonin generelated peptide-positive neurons. Levels of pro-apoptotic active caspase-3, Bax and low-affinity nerve growth factor (NGF) were increased in DRG. The concentration of anti-apoptotic heat shock protein (HSP) 70 in DRG was decreased, whereas concentrations of Bcl-xl and HSP27 were unaltered. Levels of poly(ADP-ribose) polymerase (PARP) and cleaved PARP were unaltered. Levels of NGF in sciatic nerve and concentrations of
\end{abstract}

Electronic supplementary material Supplementary material is available for this article at http://dx.doi.org/10.1007/s00125-006$0379-0$ and is accessible to authorised users.

H. Kamiya $\cdot$ W. Zhang $\cdot$ A. A. F. Sima $(\bowtie)$

Department of Pathology, Wayne State University,

School of Medicine, Scott Hall 9275,

540 E. Canfield Avenue,

Detroit, MI 48201, USA

e-mail: asima@med.wayne.edu

A. A. F. Sima

Department of Neurology, Wayne State University,

School of Medicine,

Detroit, MI, USA

H. Kamiya $\cdot$ W. Zhang $\cdot$ A. A. F. Sima

Morris Hood Jr Comprehensive Diabetes Center,

Wayne State University, School of Medicine,

Detroit, MI, USA the high-affinity NGF receptor, insulin receptor and IGF-I receptor in DRG were significantly decreased. Sensory nerve conduction velocity decreased to $78 \%$ of normal. Hyperalgesia increased up to 6 months. Myelinated and unmyelinated fibre numbers of the sural nerve were significantly decreased in diabetic rats. DRG examinations revealed no evidence of apoptosis, mitochondrial changes or abnormalities of the endoplasmic reticulum. Instead, neurons demonstrated progressive vacuolar degenerative changes of the Golgi apparatus, with fragmentation and formation of large cytoplasmic vacuoles. These data show that sustained apoptotic stress is present in DRG of chronically diabetic BB/Wor rats, but fails to proceed to apoptotic cell death.

Conclusions/interpretation Progressive DRG neuronal loss, particularly of small neurons, occurs in the type 1 diabetic $\mathrm{BB} /$ Wor rat. This is associated with neurotrophic withdrawal and progressive degeneration of the Golgi apparatus.

Keywords Apoptosis · Diabetic neuropathy ·

Dorsal root ganglion cells · Golgi apparatus .

Neuronal degeneration

$\begin{array}{ll}\text { Abbreviations } \\ \text { BB/Wor } & \text { BioBreeding/Worcester } \\ \text { CGRP } & \begin{array}{l}\text { calcitonin gene-related peptide } \\ \text { diabetic polyneuropathy }\end{array} \\ \text { DPN } & \text { dorsal root ganglion } \\ \text { DRG } & \text { heat shock cognate } 70 \\ \text { HSC70 } & \text { heat shock protein } \\ \text { HSP } & \text { nerve growth factor } \\ \text { NGF } & \text { low-affinity NGF receptor } \\ \text { NGFR-p75 } & \text { high-affinity NGF receptor } \\ \text { NGFR-TrkA } & \text { poly(ADP-ribose) polymerase } \\ \text { PARP } & \text { substance P } \\ \text { SP } & \text { streptozotocin-induced diabetic } \\ \text { STZ-D } & \end{array}$




\section{Introduction}

Diabetic polyneuropathy (DPN) is a common peripheral neuropathy and the most common late complication of diabetes. Besides hyperglycaemia-induced metabolic abnormalities resulting in polyol pathway hyperactivity, advanced glycation end-products, oxidative stress and altered protein kinase $\mathrm{C}$ activity, suppressed availability of insulin/C-peptide and impaired neurotrophic support play prominent roles in the development of DPN [1-8].

In the past few years, several studies have claimed high apoptotic rates affecting dorsal root ganglion (DRG) neurons in streptozotocin-induced diabetic (STZ-D) rats, which have been related to mitochondrial dysfunction and oxidative stress [9-11]. However, DRG neuronal apoptosis does not correspond to an equivalent loss of sensory peripheral nerve fibres in STZ-D rats $[12,13]$. Other investigators have failed to show DRG neuronal loss in chronically diabetic STZ-D rats $[13,14]$ or in subacutely diabetic BioBreeding/Worcester (BB/Wor) rats [15]. Thus DRG neuronal cell death and its relationship to apoptosis in DPN remains a controversial issue.

The diabetic BB/Wor rat develops diabetes spontaneously as a result of an autoimmune-mediated beta cell destruction, similar to that seen in human type 1 diabetes [16]. They require exogenous insulin supplementation and develop a progressive neuropathy that is functionally and structurally similar to type 1 human DPN $[8,17]$. Using this animal model we earlier failed to detect evidence of apoptotic DRG neuronal loss in 4-month diabetic rats [15]. This study did, however, demonstrate apoptotic stress in DRG neurons, which appeared to be counterbalanced by the induction of anti-apoptotic elements, thereby preventing DRG neurons from succumbing to apoptotic cell death.

To explore the possibility that DRG neuronal apoptosis occurs in long-term diabetic rats, which demonstrate significant loss of peripheral sensory fibres [17], we examined 10 -month diabetic $\mathrm{BB} /$ Wor rats.

\section{Materials and methods}

Animals Pre-diabetic BB/Wor rats and age-matched nondiabetes-prone $\mathrm{BB}$ rats were obtained from Biomedical Research Models (Worcester, MA, USA). All rats had free access to water and rat chow. Body weight, urine volume and glucosuria (Keto-Diastix; Bayer, Elkhart, IN, USA) were monitored daily to ascertain onset of diabetes and to titrate appropriate daily insulin doses for the duration of diabetes. Diabetic rats received daily doses of protamine zinc insulin varying from 0.5 to $3.0 \mathrm{U} /$ day (Blue Ridge Pharmaceuticals, Greensboro, NC, USA) to maintain blood glucose levels between 20.0 and $25.0 \mathrm{mmol} / \mathrm{l}$ and to prevent ketoacidosis. Blood glucose was measured biweekly. Animals were cared for in accordance with the guidelines of the Animal Investigation Committee, Wayne State University and those of the NIH (publication no. 85-23, 1995).

Measurement of serum insulin, C-peptide and IGF-I levels Serum was collected at the time of killing after 10 months of diabetes. Serum insulin, C-peptide and IGF-I levels were measured using RIA kits (Linco Research, St Charles, MO, USA).

Electrophysiology Rats were anaesthetised with i.p. pentobarbital sodium ( $50 \mathrm{mg} / \mathrm{kg}$ body weight). Body temperature was maintained at $36-37^{\circ} \mathrm{C}$ by a heating pad and monitored by a rectal probe. Sensory nerve conduction velocity was recorded in the right hind limb using a Cadwell 5200A Electromyographer (Cadwell Laboratories, Kennewick, WA, USA) as previously described [7, 18]. The digital nerves of the second toe were stimulated with square pulses of $0.05 \mathrm{~ms}$ duration using supramaximal currents. Action potentials were recorded at the level of the medial malleolus. The distance between stimulating and recording electrodes was $25 \mathrm{~mm}$ and that between the active recording and indifferent electrode was $10 \mathrm{~mm}$. Eight to 16 responses were averaged. The distance between stimulating and active recording electrodes was divided by the latency to the peak of the negative deflection.

Thermal plantar test Latencies of hind paw withdrawal to thermal stimulation $\left(42^{\circ} \mathrm{C} ; 152 \mathrm{~mW} / \mathrm{cm}^{2}\right)$ was measured monthly using a UGO Biological Research apparatus (Comerio, Italy) [7]. The time from heat source activation to the animal's self-withdrawal in seconds was measured six times in alternating hind paws. The mean of these measurements was calculated and used as the measure of latency. This measurement reflects fibres conducting temperature sensation, including unmyelinated and small myelinated fibres.

Tissue collection Ten months after onset of diabetes, animals were anaesthetised with an i.p. overdose of sodium pentobarbital $(120 \mathrm{mg} / \mathrm{kg}$ body weight). Three control and three BB/Wor rats were perfused with $\sim 500 \mathrm{ml}$ of $4 \%$ paraformaldehyde fixative. The left L5 DRG were post-fixed in situ for $10 \mathrm{~min}$ in $1 \%$ cacodylate buffered (pH 7.4) 2.5\% glutaraldehyde. They were post-fixed in $1 \%$ cacodylate buffered $(\mathrm{pH}$ 7.4) osmium tetroxide, dehydrated and embedded in Epon for morphometric analysis.

The right DRG were fixed by immersion in $4 \%$ paraformaldehyde in $0.1 \mathrm{~mol} / 1$ phosphate buffer $(\mathrm{pH} 7.4)$ 
overnight at $4^{\circ} \mathrm{C}$, rinsed in PBS, dehydrated, immersed in xylene and embedded in paraffin. L4 and L5 DRG and sciatic nerves were collected from five diabetic and five control rats for protein extraction. Tissues were snap frozen in liquid nitrogen and kept at $-80^{\circ} \mathrm{C}$ until use.

Sural nerves were exposed in diabetic and control rats and fixed in situ for $10 \mathrm{~min}$ in $1 \%$ cacodylate buffered (pH 7.4) $2.5 \%$ glutaraldehyde, excised and immersed in the same fixative for $2 \mathrm{~h}$ at $4^{\circ} \mathrm{C}$. They were post-fixed in $1 \%$ cacodylate buffered ( $\mathrm{pH}$ 7.4) osmium tetroxide, dehydrated and embedded in Epon for morphometric analysis.

Morphometry Morphometric analyses of DRG neurons were performed on toluidine-blue-stained step-wise sections (0.5$\mu \mathrm{m}$ thick; $40 \mu \mathrm{m}$ apart) using a video image analysis system (Image-Pro Plus 3.0; Media Cybernetics, Silver Spring, MD, USA). L5 ganglia were sectioned, 36-47 sections per ganglion. Neurons with distinguishable nuclei were counted and their total areas measured. Diameters of nuclei were measured and averaged. The number of neurons per DRG was calculated as the sum of numbers of neurons per section $\times 40$ /mean nuclear diameter [15].

Semithin $(0.5 \mu \mathrm{m})$ cross-sections of Epon-embedded sural nerves stained with toluidine-blue were prepared for light microscopic morphometric analysis using a computerised image analysis system (Image-1; Universal Imaging, West Chester, PA, USA). This system is programmed to assess the total complement of sural nerve myelinated fibres and provides the following parameters: fascicular area $\left(\mu \mathrm{m}^{2}\right)$, number of fibres, fibre density (number $/ \mathrm{mm}^{2}$ ), mean fibre area $\left(\mu \mathrm{m}^{2}\right)$, mean axonal area $\left(\mu \mathrm{m}^{2}\right)$, mean myelin area $\left(\mu \mathrm{m}^{2}\right)$, axon/myelin ratio, and index of circularity and fibre occupancy rate (in \%) as previously described [19].

For morphometric analyses of unmyelinated fibres, ultrathin cross-sections of sural nerves were obtained with the aid of an LKB ultramicrotome (Marviac Limited, Halifax, Canada) and stained with uranyl acetate and lead citrate. They were examined with a Zeiss 12AS electron microscope (Carl Zeiss, Oberkochen, Germany). Systematically selected frames representing approximately $30 \%$ of the sural nerve cross-sectional area were obtained. Photographs were enlarged 10,000 times, scanned and downloaded to the computerised image analysis system. It should be noted that unmyelinated fibres of the sural nerve include also sympathetic fibres. The following morphometric parameters of unmyelinated fibres were obtained: unmyelinated fibre number, fibre density (number $/ \mathrm{mm}^{2}$ ), mean fibre size $\left(\mu \mathrm{m}^{2}\right)$, axon numbers per Schwann cell unit and the frequencies of collagen pockets, denervated Schwann cell profiles, type 2 Schwann cell/axon relationship and regenerating C-fibres [18]. The latter are recognised by duplication of the basement membrane of the supporting Schwann cell.
Structural changes of DRG Semithin $(0.5 \mu \mathrm{m})$ toluidineblue-stained sectioned DRG were examined for margination of nuclear chromatin, apoptotic bodies, degenerative changes and nodules of Nageotte. For further evaluation of degenerative changes, ultrathin sections of DRG were stained with uranyl acetate and lead citrate, and examined ultrastructurally.

Immunohistochemistry for substance $P(S P)$, calcitonin gene-related peptide (CGRP), heat shock protein (HSP) 27, HSP70 and active caspase-3 in DRG Six-micron-thick sections were immunostained using an avidin-biotin complex kit (Vector Laboratories, Burlingame, CA, USA). Primary antibodies used are listed in Table 1 of the Electronic Supplementary Material (ESM). Quantifications of positive neurons were performed using the same image analysis system as described above. Images of three serially sectioned DRG (60 $\mu \mathrm{m}$ apart) were captured and assessed using a binary scale. In each section 200-300 ganglion cells with visible nuclei were captured. The number and areas of SP- and CGRP-positive neurons were determined in each section. The frequencies of SP- and CGRP-positive neurons per ganglion were calculated as: neurons per ganglion $\times$ positive neurons per section/total neurons per section [15]. The frequencies of HSP27-, HSP70- and active caspase-3positive neurons were calculated from parallel serial sections.

Measurement of SP and CGRP contents of DRG Enzyme immunometric assays (EIAs) were used to assess SP (Cayman Chemical Co., Ann Arbor, MI, USA) and CGRP (SPIbio Co., Massy, Cedex, France) in DRG. Pairs of L4 and L5 DRG were homogenised in $2 \mathrm{~mol} / \mathrm{l}$ acetic acid buffer (including $1 \mu \mathrm{g} / \mathrm{ml}$ aprotinin and $1 \mu \mathrm{g} / \mathrm{ml}$ leupeptin), then boiled for $10 \mathrm{~min}$. After centrifuging at 10,000 g for $30 \mathrm{~min}$, the supernatants were freeze-dried and dissolved in EIA buffer. The assays were processed in duplicates. Results were expressed as picogram per ganglion [18].

Western blotting Pairs of L4 and L5 DRG were lysed in detergent lysis buffer $(50 \mathrm{mmol} / \mathrm{l}$ Tris-HC1, pH 7.4, $150 \mathrm{mmol} / 1 \mathrm{NaCl}, 1 \mathrm{mmol} / \mathrm{l}$ EDTA, $1 \%$ Triton X-100, $1 \mathrm{mmol} / \mathrm{l}$ phenylmethylsulphonyl fluoride, $1 \mu \mathrm{g} / \mathrm{ml}$ leupeptin and $1 \mu \mathrm{g} / \mathrm{ml}$ aprotinin) and centrifuged at $10,000 \mathrm{~g}$ for $20 \mathrm{~min}$ at $4^{\circ} \mathrm{C}$. DRG protein $(10-40 \mu \mathrm{g})$ was separated by $7.5-15 \%$ SDS-PAGE, and transferred to polyvinylidene difluoride membranes (Bio-Rad, Hercules, CA, USA). Membranes were blocked with Tween-20-Tris-buffered saline $(10 \mathrm{mmol} / 1 \mathrm{Tris}-\mathrm{HC} 1, \mathrm{pH} 7.5,100 \mathrm{mmol} / \mathrm{l} \mathrm{NaC1}$ and $0.1 \%$ Tween-20) containing $5 \%$ non-fat dry milk (Bio-Rad) prior to incubation with primary antibodies (see Table 1 of ESM). Antigen detection was performed using chemiluminescence (Amersham Pharmacia Biotech, Piscataway, NJ, USA) with horseradish peroxidase-conjugated secondary antibodies. 
Membranes were exposed to Biomax film (Kodak, Rochester, NY, USA). Images were scanned and densities determined using a Bio-Rad Fluoro-S multi-imager. Expression of proteins was corrected for by actin density and expression in control animals was arbitrarily set to 1.0 .

Nerve growth factor (NGF) analyses Sciatic NGF content was determined using a quantitative two-site enzyme immunoassay (Emax Immunoassay System; Promega, Madison, WI, USA). Assays were performed according to the manufacturer's protocol and results were expressed as picogram per milligram of protein as previously described [18].

Statistical analysis All values are expressed as means $\pm \mathrm{SD}$. Significance of differences was analysed by ANOVA. Group differences were assessed by Scheffé's test. Significance was defined as a $p$ value of less than 0.05. All analyses were performed by personnel unaware of the animal identities.

\section{Results}

Clinical findings Diabetes-prone $\mathrm{BB} /$ Wor rats developed type 1 diabetes at $73 \pm 2$ days of age and were maintained at hyperglycaemic levels (20-25 mmol/1 glucose) throughout the observation period (Table 1). After a 10-month duration of diabetes, they showed decreased fasting serum insulin (11.5\% of normal; $p<0.001)$, C-peptide $(<3.3 \%$ of normal; $p<0.001)$ and IGF-I (62.7\% of normal; $p<0.001)$ levels (Table 1). Sensory nerve conduction velocity decreased progressively to $78 \%$ of normal $(p<0.001)$ at 10 months of diabetes (Table 1). Small fibre function was measured as latencies of hind paw withdrawal to thermal stimuli. They decreased progressively to $39.4 \%(p<0.001)$ of normal at 6 months, reflecting hyperalgesia, and then reversed to normal at 10 months (Fig. 1).
Morphometric analyses The number of DRG neurons were reduced by $25 \%(p<0.01)$ at 10 months of diabetes and remaining neurons showed a $30 \%(p<0.05)$ reduction in size (Table 2 and Fig. 2a). The neuronal loss was entirely accounted for by the loss of SP- $(p<0.001)$ and CGRP$(p<0.005)$ positive neurons (Table 2$)$. The mean size of remaining SP and CGRP neurons was decreased by $22.6 \%$ $(p<0.05)$ and $23.6 \%$, respectively, $(p<0.005)$ (Table 2, Fig. 2b,c).

For morphological examinations, $937 \pm 3$ neurons per DRG were examined from toluidine-blue-stained sections. No margination of nuclear chromatin, membrane blebbing or apoptotic figures were observed in control or diabetic rats. No cellular oedema or disruption of the plasma membrane, indicative of early necrosis, was found. Both control and diabetic rats showed subplasmalemmal small vacuoles coalescing into larger cytoplasmic vacuoles (Fig. 3a,b). Nodules of Nageotte were observed in control and diabetic rats. The frequencies of neurons containing small subplasmalemmal vacuoles $(p<0.05)$, large cytoplasmic vacuoles $(p<0.05)$ and nodules of Nageotte $(p<0.05)$ were increased in diabetic rats (Table 2). Large cytoplasmic vacuoles were 1.7-fold more frequent in small neurons $\left(<1,000 \mu \mathrm{m}^{2}\right)$ in diabetic rats and three-fold more frequent in control animals compared with the frequencies in large neurons $\left(>1,000 \mu^{2}\right)$ (data not shown).

Examination of sural nerve myelinated fibres showed decreased fascicular areas in diabetic rats $(p<0.001)$ (Table 3 ). The number of myelinated fibres was decreased $(p<0.005)$, accompanied by decreased myelinated fibre size $(p<0.001)$, decreased axonal size $(p<0.001)$ and myelin area $(p<0.01)$ in diabetic rats (Table 3$)$. Decreased endoneurial occupancy of myelinated fibres $(p<0.05)$ and index of circularity $(p<0.05)$ of myelinated fibres were seen in diabetic rats (Table 3 ).

Unmyelinated fibre morphometry revealed a $56.0 \%$ fibre loss $(p<0.001)$, decreased fibre density $(p<0.001)$, axonal atrophy $(p<0.005)$ and decreased number of axons per Schwann cell unit $(p<0.001)$ in diabetic rats. These changes were accompanied by increased frequencies of denervated Schwann cell profiles $(p<0.05)$, collagen pockets in

Table 1 Body weight, blood glucose levels, serum insulin, C-peptide and IGF-I levels and sensory nerve conduction velocity (SNCV) in 10-month control and diabetic $\mathrm{BB} /$ Wor rats

\begin{tabular}{llllll}
\hline & $\begin{array}{l}\text { Body weight } \\
(\mathrm{g})(n=8)\end{array}$ & $\begin{array}{l}\text { Blood glucose } \\
(\mathrm{mmol} / \mathrm{l})(n=8)\end{array}$ & $\begin{array}{l}\text { Serum insulin } \\
(\mathrm{pmol} / \mathrm{l})(n=5)\end{array}$ & $\begin{array}{l}\text { Serum C-peptide } \\
(\mathrm{pmol} / \mathrm{l})(n=5)\end{array}$ & $\begin{array}{l}\text { Serum IGF-I } \\
(\mathrm{ng} / \mathrm{ml})(n=5)\end{array}$ \\
\hline Control rats & $555 \pm 29$ & $5.0 \pm 0.3$ & $442 \pm 36$ & $754 \pm 63$ & $\begin{array}{l}\text { SNCV } \\
(\mathrm{m} / \mathrm{s})(n=8)\end{array}$ \\
BB/Wor rats & $400 \pm 13^{\mathrm{a}}$ & $23.2 \pm 1.3^{\mathrm{a}}$ & $51 \pm 5^{\mathrm{a}}$ & $<25^{\mathrm{a}}$ & $\begin{array}{l}4,192 \pm 37 \\
747 \pm 86^{\mathrm{a}}\end{array}$ \\
\hline
\end{tabular}

Results are means \pm SD.

${ }^{\mathrm{a}} p<0.001$ vs control rats 


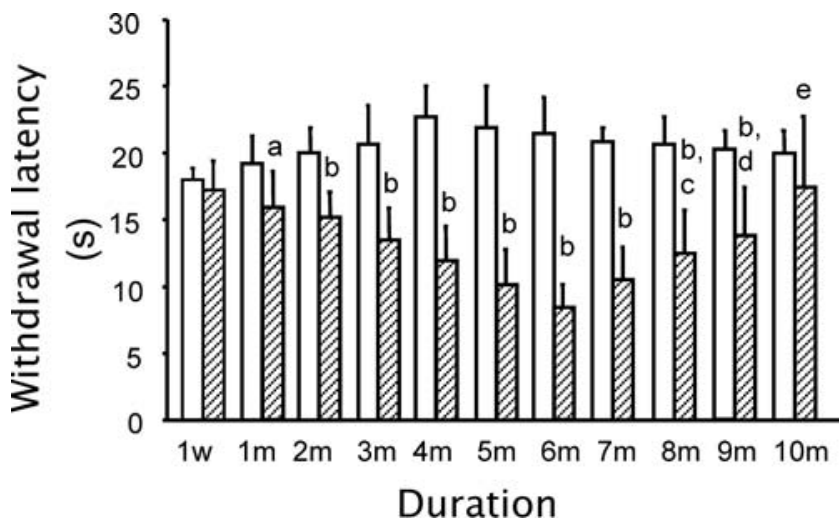

Fig. 1 Latency (in s) of hind paw withdrawal to thermal stimulation (withdrawal latencies) in $\mathrm{BB} /$ Wor rats (hatched bars, $n=8$ ) and control rats (empty bars, $n=8$ ). Results are means $\pm \mathrm{SD}$. ${ }^{\mathrm{a}} p<0.05,{ }^{\mathrm{b}} p<0.001 \mathrm{vs}$ respective control rats. ${ }^{\mathrm{c}} p<0.05,{ }^{\mathrm{d}} p<0.005,{ }^{\mathrm{e}} p<0.001$ vs 6 -month diabetic rats. $w$, weeks; $m$ months

Schwann cells $(p<0.05)$, type 2 Schwann cell/axon relationships $(p<0.001)$ and regenerating fibres $(p<0.05)$ in diabetic rats (Table 3 ).

Ultrastructural changes in DRG Examination of DRG from both diabetic and control animals showed cytoplasmic vacuoles lined by single membranes and containing membranous debris (Fig. 3a-c). The neuronal cytoplasm contained normal-appearing mitochondria and rough endo-

Table 2 Morphometry and morphology of DRG, and SP and CGRP contents

\begin{tabular}{|c|c|c|}
\hline & $\begin{array}{l}\text { Control } \\
\text { rats }\end{array}$ & $\begin{array}{l}\mathrm{BB} / \text { Wor } \\
\text { rats }\end{array}$ \\
\hline Mean neuronal area $\left(\mu \mathrm{m}^{2}\right)(n=3)$ & $947.2 \pm 125.4$ & $664.8 \pm 101.2^{\mathrm{a}}$ \\
\hline Number of neurons/ganglion $(n=3)$ & $13,582 \pm 61$ & $9,968 \pm 1,047^{\mathrm{b}}$ \\
\hline SP content (pg/ganglion) $(n=5)$ & $105.5 \pm 18.7$ & $62.7 \pm 19.7^{\mathrm{b}}$ \\
\hline SP-positive neurons $(\%)(n=3)$ & $25.6 \pm 1.4$ & $19.3 \pm 0.9^{\mathrm{c}}$ \\
\hline $\begin{array}{l}\text { Mean area of SP-positive } \\
\text { neurons }(n=3)\left(\mu \mathrm{m}^{2}\right)\end{array}$ & $442.1 \pm 32.2$ & $342.1 \pm 32.9^{\mathrm{a}}$ \\
\hline $\begin{array}{l}\text { SP-positive neurons/ganglion } \\
(n=3)\end{array}$ & $3,476 \pm 250$ & $1,919 \pm 126^{\mathrm{d}}$ \\
\hline CGRP content (pg/ganglion) $(n=5)$ & $816.8 \pm 80.0$ & $475.5 \pm 71.6^{\mathrm{d}}$ \\
\hline CGRP-positive neurons $(\%)(n=3)$ & $33.0 \pm 2.2$ & $23.5 \pm 0.7^{\mathrm{c}}$ \\
\hline $\begin{array}{l}\text { Mean area of CGRP-positive } \\
\text { neurons }\left(\mu \mathrm{m}^{2}\right)(n=3)\end{array}$ & $511.0 \pm 19.7$ & $390.5 \pm 20.8^{\mathrm{c}}$ \\
\hline $\begin{array}{l}\text { CGRP-positive } \\
\text { neurons/ganglion }(n=3)\end{array}$ & $4,488 \pm 479$ & $2,338 \pm 150^{\mathrm{c}}$ \\
\hline $\begin{array}{l}\text { Small vacuoles } \\
\text { (\% of total neurons) }(n=3)\end{array}$ & $13.2 \pm 1.2$ & $17.7 \pm 1.5^{\mathrm{a}}$ \\
\hline $\begin{array}{l}\text { Large vacuoles } \\
\text { ( } \% \text { of total neurons) }(n=3)\end{array}$ & $0.14 \pm 0.06$ & $0.65 \pm 0.26^{\mathrm{a}}$ \\
\hline $\begin{array}{l}\text { Nodules of Nageotte } \\
\text { (\% of total neurons) }(n=3)\end{array}$ & $0.14 \pm 0.15$ & $0.60 \pm 0.10^{\mathrm{a}}$ \\
\hline
\end{tabular}

Results are means $\pm \mathrm{SD}$.

${ }^{\mathrm{a}} p<0.05,{ }^{\mathrm{b}} p<0.01,{ }^{\mathrm{c}} p<0.005,{ }^{\mathrm{d}} p<0.001$ vs control rats plasmic reticulum (Fig. 3c-ei). On the other hand, stacks of the Golgi apparatus commonly showed separation of individual ribbons with the formation of vacuoles of varying sizes (Fig. 3ei and eii) containing membranous debris (Fig. 3eii). These vacuoles were particularly common under the neurolemma, where they formed larger conglomerates of vacuoles (Fig. 3a,b,d), which then coalesced into larger cytoplasmic vacuoles (Fig. 3a,b). Vacuoles were surrounded by vesiculated and degenerated ribbons of Golgi (Fig. 3eiii and eiv). These changes occurred in the presence of unaltered nuclear morphology in both control and diabetic rats (Fig. 3a) but were 4.6-fold more frequent in diabetic animals (Table 2).

$S P$ and CGRP contents in DRG SP $(p<0.01)$ and CGRP $(p<0.001)$ contents in DRG were significantly decreased in diabetic rats (Table 2). These data are consistent with the decreased frequencies of SP- and CGRP-positive neurons in DRG.

Levels of active caspase-3 and caspase-3-positive neurons Western blots for active caspase-3 revealed increased $(p<0.05)$ levels in diabetic DRG (Fig. 4a). Caspase-3 immunocytochemistry showed positive cytoplasmic staining in $13.8 \%$ of neurons in control rats, and these frequencies were increased to $23.5 \%(p<0.001)$ of DRG neurons in diabetic rats (Fig. 4b). Positive nuclear staining was observed in 1.8 and $4.2 \%$ of ganglion cells in control and diabetic rats, respectively, $(p<0.01)$ (Fig. $4 \mathrm{c}$ ).

Levels of pro- and anti-apoptotic elements in DRG Mitochondrial pro-apoptotic Bax was increased 2.3-fold $(p<0.01)$ in diabetic rats (Fig. 5a). On the other hand, the anti-apoptotic Bcl-xl concentration in DRG was not altered compared with that in control rats (Fig. 5b). The concentration of the low-affinity NGF receptor (NGFR-p75), a member of the TNF death receptor family, was increased 1.35 -fold in diabetic rats $(p<0.05)$ (Fig. 5c). Levels of Fas, caspase-12, total poly(ADP-ribose) polymerase (PARP) or cleaved PARP were not significantly altered in diabetic animals (Fig. 5d-f).

Anti-apoptotic HSPs in DRG HSP27 protein was not altered in diabetic DRG (Fig. 6a). Inducible HSP70 was decreased to $49 \%(p<0.005)$ in diabetic DRG (Fig. 6c). Constitutively expressed heat shock cognate 70 (HSC70) (Fig. 6c) or HSP40 (Fig. 6d) were not significantly altered. Immunohistochemically, HSP27 was expressed in small and large neurons and axons as reported previously [15]. The frequency of HSP27-positive neurons was not changed in diabetic rats (Fig. 6e). HSP70 localised to mainly Schwann cells, satellite cells and to small neurons [15]. HSP70-positive neurons were significantly decreased in 

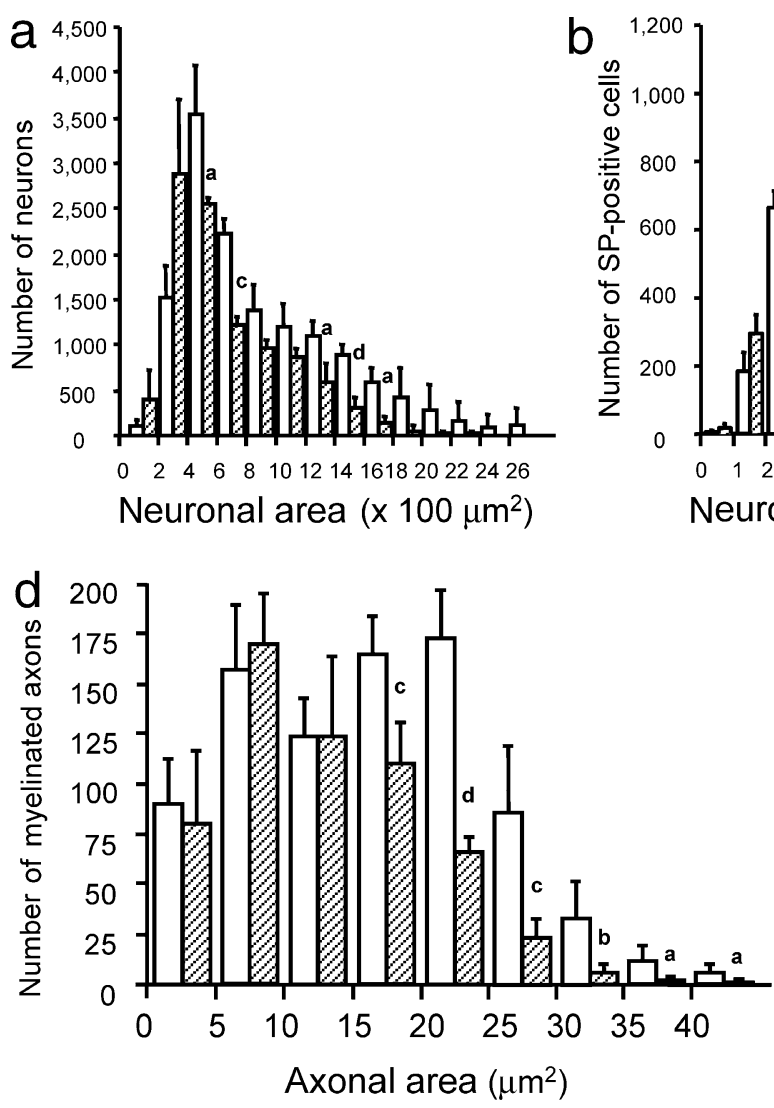

Fig. 2 Morphometric data for DRG neurons and myelinated and unmyelinated fibres of the sural nerve of $\mathrm{BB} /$ Wor rats (hatched bars) and control rats (empty bars). a Histogram of DRG neuronal size distributions of total DRG neurons $(n=3)$. b Size distribution of

diabetic rats $(p<0.05)$ (Fig. 6f), in keeping with the decrease in the number of small SP- and CGRP-positive neurons (Table 2).

Changes in neurotrophic factors Levels of IGF-I receptor $(p<0.05)$, the high-affinity neuronal insulin receptor $(p<0.05)$ and high-affinity NGF receptor (NGFR-TrkA) $(p<0.005)$ were significantly decreased in diabetic DRG neurons (Fig. $7 \mathrm{a}-\mathrm{c}$ ). The NGF content in the sciatic nerve was significantly decreased $(p<0.01)$ in diabetic rats (Fig. 7d).

\section{Discussion}

The present study shows severe neuronal loss of DRG in chronically diabetic BB/Wor rat, which is totally accounted for by the loss of nociceptive SP- and CGRP-positive neurons. The $47 \%$ loss of nociceptive neurons corresponded to a $56 \%$ loss of peripheral C-fibres in the sural nerve. Remaining $\mathrm{C}$-fibres demonstrated ongoing degener-
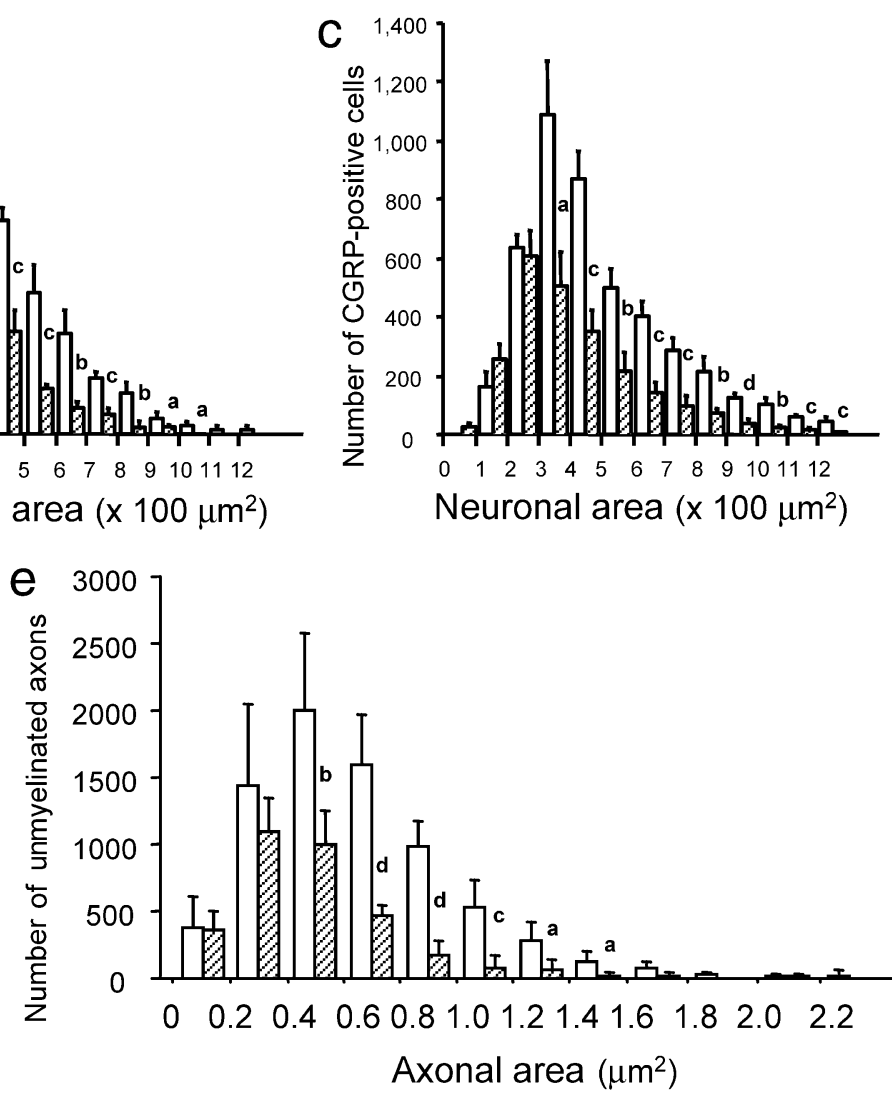

SP-positive neurons $(n=3)$. c Size distribution of CGRP-positive neurons $(n=3)$. Axonal area distributions of myelinated fibres $(n=5)$ (d) and unmyelinated fibres $(n=5)(\mathbf{e})$. Results are means \pm SD. ${ }^{\mathrm{a}} p<0.05,{ }^{\mathrm{b}} p<0.01,{ }^{\mathrm{c}} p<0.005,{ }^{\mathrm{d}} p<0.001$ vs control rats

ative changes such as fibre atrophy, type 2 Schwann cell/ axon relationships, collagen pockets and denervated Schwann cell profiles [18]. These findings indicate a significant progression of nociceptive neuropathy with duration of diabetes as compared with 4-month diabetic $\mathrm{BB} /$ Wor rats, which showed no significant loss of DRG neurons and a modest loss of peripheral C-fibres [15].

This progression is reflected in progressive nociceptive dysfunction, which increased up to 6 months of duration of diabetes with subsequent reversal of hyperalgesia. This normalisation of responses to thermal stimuli most likely reflects ensuing small fibre loss resulting in increasing loss of temperature sensation. Large DRG neurons, giving rise to myelinated peripheral fibre populations, showed no numerical loss, although they demonstrated significant atrophy. Despite this, peripheral sensory myelinated fibres of the sural nerve showed after 10 months of diabetes a $30 \%$ loss associated with significant axonal atrophy of preserved fibres. An earlier study of 11-month diabetic $\mathrm{BB} /$ Wor rats [17] showed a similar magnitude of sural nerve myelinated fibre loss, whereas the more proximal tibial nerve and L5 dorsal root revealed no changes in 

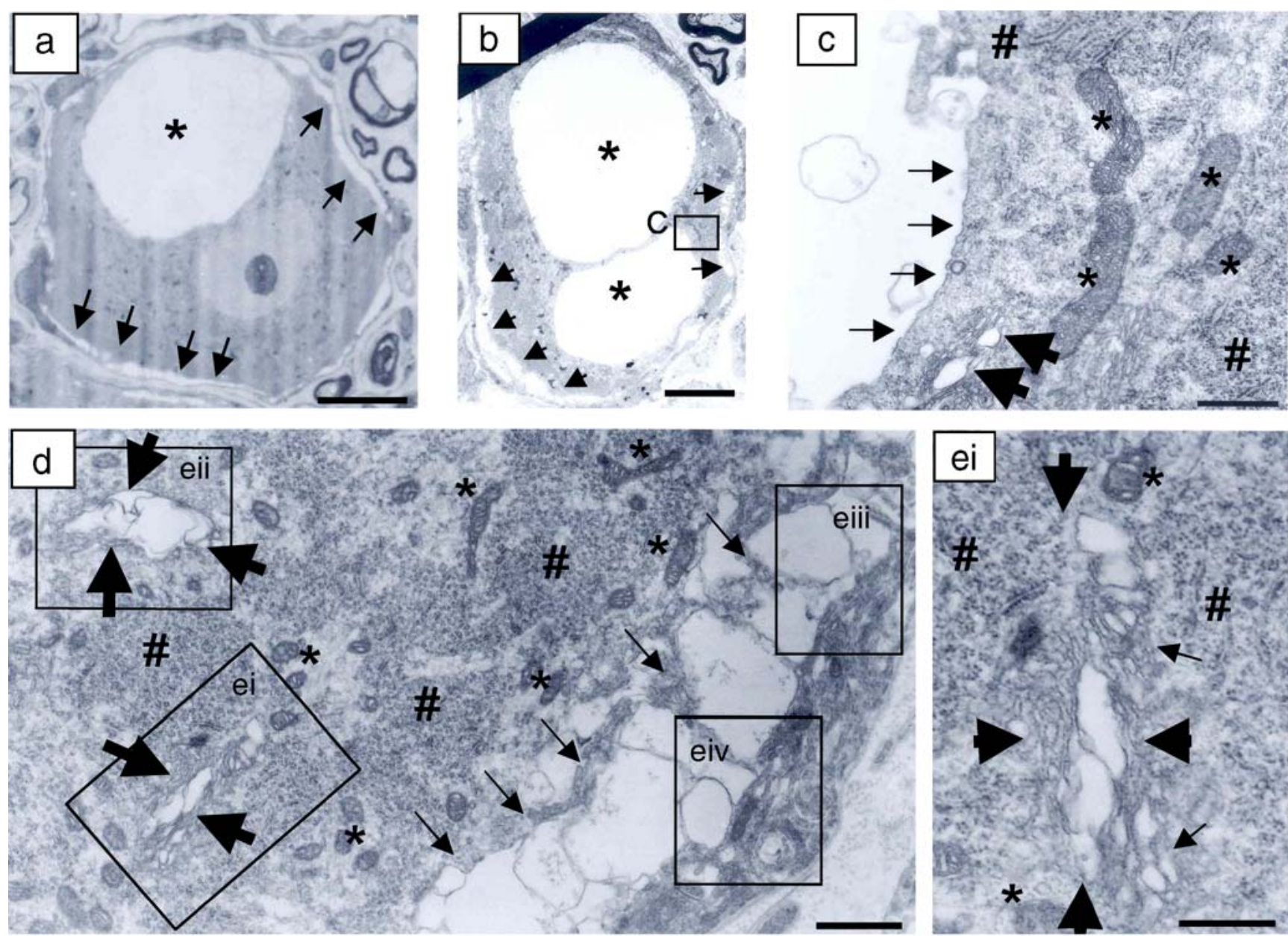
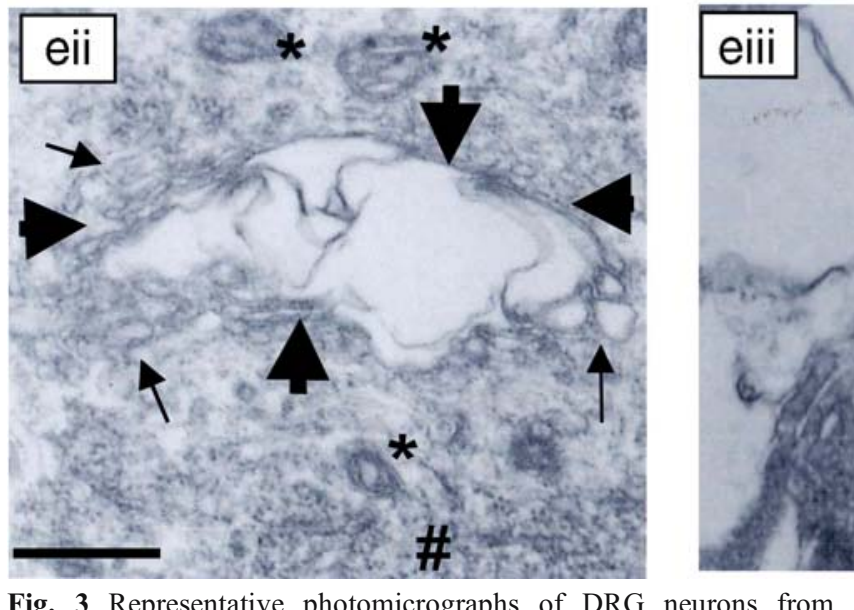

Fig. 3 Representative photomicrographs of DRG neurons from 10 -month diabetic rats showing vacuolar degeneration. a Toluidineblue-stained DRG neuron with subplasmalemmal small (arrows) and large (asterisk) vacuoles. Note normal nucleus and nucleolus. Bar $=10 \mu \mathrm{m}$. b-e Electron microscope studies of a representative diabetic DRG neurons. b Degenerative neuron showing small (arrows) and two large (asterisks) vacuoles. Bar $=7 \mu \mathrm{m}$. c Enlargement of $\mathbf{b}$. Thin arrows show vacuole lined by an intact single membrane. Bold arrows show swollen Golgi apparatus. Asterisks and \# show

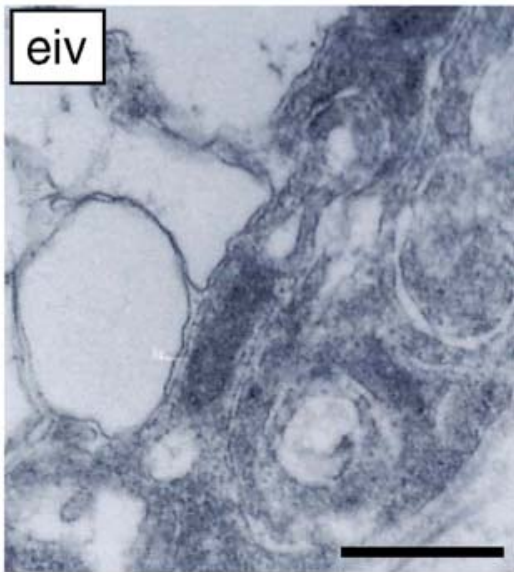

intact mitochondria and rough endoplasmic reticulum, respectively. Bar $=0.6 \mu \mathrm{m}$. d Diabetic DRG neuron showing subplasmalemmal small vacuoles (arrows), swollen Golgi apparatus (bold arrows), intact mitochondria (asterisks) and rough endoplasmic reticulum (\#). Bar $=1.1 \mu \mathrm{m}$. e Enlargement of $\mathbf{d}$ (all bars $=0.6 \mu \mathrm{m}$ ), showing swollen Golgi apparatus (bold arrows), vesiculation of Golgi ribbons (thin arrows), intact mitochondria (asterisks) and rough endoplasmic reticulum (\#) (ei and eii). eiii, eiv layered Golgi structures next to small vacuoles 
Table 3 Morphometry of the sural nerve

\begin{tabular}{lll}
\hline Morphometric parameters & Control rats $(n=5)$ & BB/Wor rats $(n=5)$ \\
\hline Myelinated fibres & & $36,917 \pm 2,411^{\mathrm{d}}$ \\
Fascicular area $\left(\mu \mathrm{m}^{2}\right)$ & $56,028 \pm 4,386$ & $588 \pm 70^{\mathrm{c}}$ \\
Number of myelinated fibres & $836 \pm 106$ & $15,925 \pm 1,668$ \\
Myelinated fibre density $\left(n / \mathrm{mm}^{2}\right)$ & $14,899 \pm 1,238$ & $31.4 \pm 1.5^{\mathrm{d}}$ \\
Mean myelinated fibre area $\left(\mu \mathrm{m}^{2}\right)$ & $38.9 \pm 2.0$ & $12.4 \pm 0.8^{\mathrm{d}}$ \\
Mean axonal area $\left(\mu \mathrm{m}^{2}\right)$ & $16.2 \pm 1.1$ & $19.0 \pm 1.5^{\mathrm{b}}$ \\
Mean myelin area $\left(\mu \mathrm{m}^{2}\right)$ & $22.7 \pm 1.7$ & $50.0 \pm 5.8^{\mathrm{a}}$ \\
Myelinated fibre occupancy rate $(\%)$ & $57.9 \pm 4.6$ & $0.65 \pm 0.07$ \\
Axon/myelin ratio $\left(\mu \mathrm{m}^{2} / \mu \mathrm{m}^{2}\right)$ & $0.72 \pm 0.07$ & $0.90 \pm 0.03^{\mathrm{a}}$ \\
Index of circularity & $0.92 \pm 0.01$ & \\
Unmyelinated fibres & & $0.487 \pm 0.076^{\mathrm{c}}$ \\
Mean unmyelinated fibre area $\left(\mu \mathrm{m}^{2}\right)$ & $0.676 \pm 0.056$ & $3,315 \pm 244^{\mathrm{d}}$ \\
Number of unmyelinated fibres & $7,537 \pm 1,229$ & $89,867 \pm 5,004^{\mathrm{d}}$ \\
Unmyelinated fibre density $\left(\mathrm{n} / \mathrm{mm}^{2}\right)$ & $134,450 \pm 18,371$ & $4.03 \pm 0.26^{\mathrm{d}}$ \\
Axon numbers/Schwann cell unit $(n /$ unit) & $5.20 \pm 0.34$ & $4.42 \pm 1.32^{\mathrm{a}}$ \\
Denervated Schwann cell profiles (percent of total unmyelinated fibres) & $2.54 \pm 0.90$ & $11.60 \pm 3.36^{\mathrm{a}}$ \\
Collagen pockets (percent of total unmyelinated fibres) & $7.98 \pm 0.49$ & $18.22 \pm 2.36^{\mathrm{d}}$ \\
Type 2 Schwann cell/axon relationship (percent of total unmyelinated fibres) & $6.04 \pm 1.47$ & $8.56 \pm 3.13^{\mathrm{a}}$ \\
Regenerating fibres (percent of total unmyelinated fibres) & $4.28 \pm 1.24$ & \\
\hline
\end{tabular}

Results are means $\pm \mathrm{SD}$.

${ }^{\mathrm{a}} p<0.05,{ }^{\mathrm{b}} p<0.01,{ }^{\mathrm{c}} p<0.005,{ }^{\mathrm{d}} p<0.001$ vs control rats

myelinated fibre numbers. This is consistent with preservation of large DRG neurons giving rise to myelinated fibres. Taken together the findings are therefore in keeping with a dying-back process rather than apoptotic neuronal loss as the cause of distal axonal loss. However, we cannot categorically exclude the possibility that a low frequency of apoptotic neuronal death may occur that has escaped detection in the present and previous study [15]. Apoptotic neuronal death is a rapid event with consequent Wallerian degeneration of corresponding axonal processes, a structural change that is infrequent in the BB/Wor rat $[1,19]$. Previous studies examining 12-month STZ-D rats failed to demonstrate DRG neuronal loss [13, 14], which is consistent with a retained number of peripheral myelinated fibre number in the STZ-D rat $[12,13]$. Differences in insulin and C-peptide deficiencies may account for these discrepancies between the STZ and BB/Wor models [7, 16, 20].

Some studies have suggested that neuronal loss of DRG in STZ-D rats is due to apoptotic cell death induced by mitochondrial dysfunction secondarily to oxidative stress [9-11]. In the present study, we failed to identify any morphological evidence of apoptosis in DRG neurons, nor could we show structural abnormalities of neuronal mitochondria. Instead, one of the most intriguing and surprising findings in the present study was the progressive degenerative changes involving the Golgi apparatus, with formation of membrane-bound vacuoles, fragmentation and vesiculation of Golgi stacks. The frequency of large cytoplasmic vacuoles in DRG neurons increased in both diabetic and control animals when compared with 4-month diabetic animals [15], although they were almost five-fold more
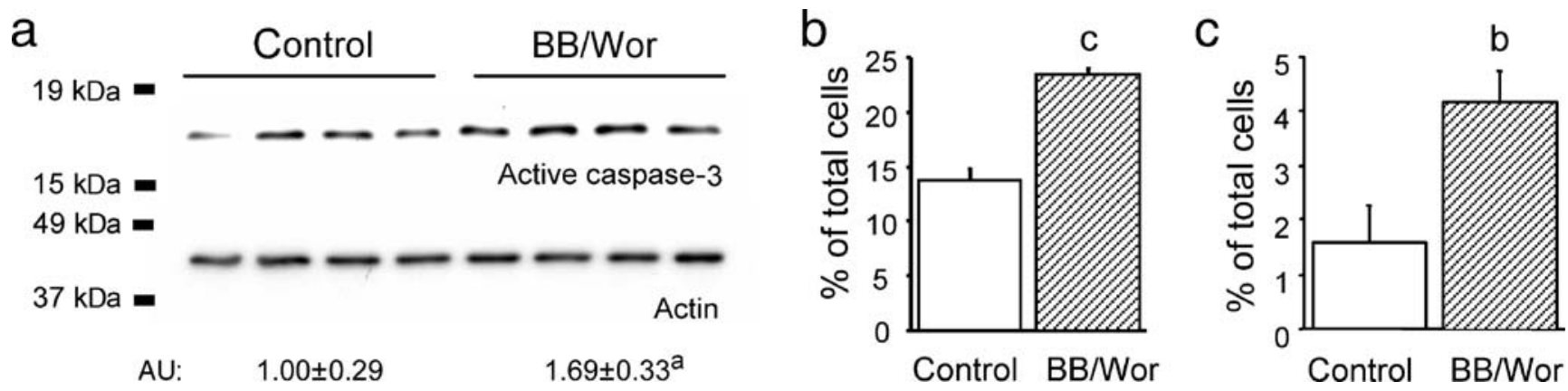

Fig. 4 a Concentration of active caspase-3 in DRG $(n=4)$. b Quantitative analyses of neurons showing active caspase-3 stainability in the cytoplasm $(n=3)$ and $\mathbf{c}$ in their nuclei $(n=3)$. Results are means \pm SD. ${ }^{\mathrm{a}} p<0.05,{ }^{\mathrm{b}} p<0.01,{ }^{\mathrm{c}} p<0.001$ vs control rats 


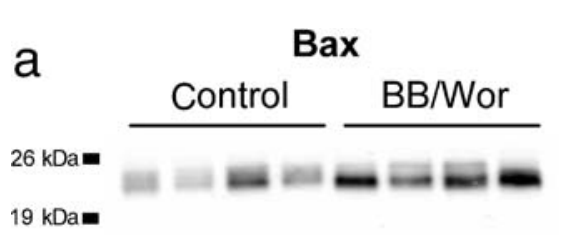

AU: $1.00 \pm 0.52 \quad 2.30 \pm 0.43^{b}$

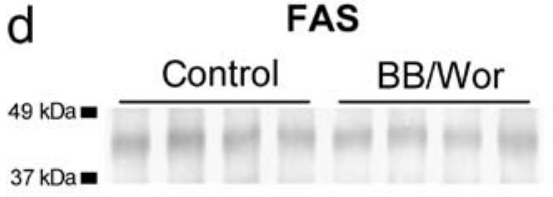

AU: $1.00 \pm 0.19 \quad 0.85 \pm 0.08$

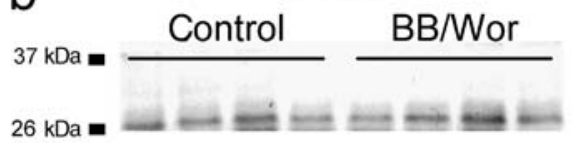

$A U: 1.00 \pm 0.24 \quad 1.03 \pm 0.35$ b Bcl-xl

C NGFR-p75

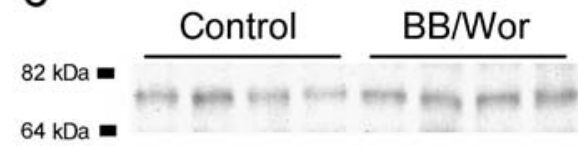

AU: $1.00 \pm 0.20$

$1.35 \pm 0.15^{a}$

f Cleaved and total PARP

e $\quad$ Caspase 12

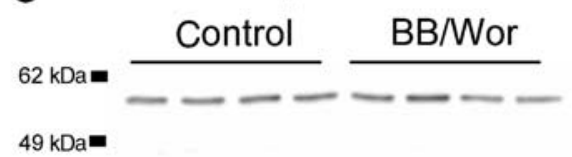

AU: $1.00 \pm 0.08 \quad 0.96 \pm 0.28$

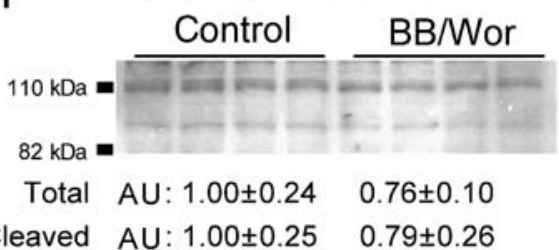

Fig. 5 Levels of pro- and anti-apoptotic elements in DRG. a Bax, b Bcl-xl, c NGFR-p75, d Fas, e caspase-12, and f cleaved and total PARP (all $n=4$ ) are shown. Results are means \pm SD. ${ }^{\mathrm{a}} p<0.05,{ }^{\mathrm{b}} p<0.01$ vs control rats

frequent in diabetic animals. Large vacuoles were 1.7 -fold more frequent in small $\left(<1,000 \mu \mathrm{m}^{2}\right)$ compared with large diabetic DRG neurons at 10 months, despite the substantial loss of small neurons. Even in control animals, $75 \%$ of large vacuoles were found in small neurons, although their overall frequency was only $22 \%$ of that found in diabetic rats. These findings parallel a greater susceptibility to neurotrophic withdrawal, including insulin, of small DRG neurons. Normal age-related suppression and impaired sensitivity to such support may underlie similar qualitative changes of the Golgi in aged rats.

The Golgi complex is essential for processing and sorting of lipids and proteins [21]. It co-localises with an array of cytoskeletal binding proteins and is linked to microtubules [22, 23]. The Golgi structure is one of several stress-sensing organelles [24, 25], which during apoptotic stress becomes disassembled secondarily to changes in the Golgi exoskeleton [26]. The upstream initiator caspase, caspase-2, has been implicated in Golgi disassembly by cleavage of golgin-160 [27], whereby death receptors like the TNF receptor family and Fas are involved [26, 28, 29]. In the present study, although we demonstrated significant upregulation of the death receptor NGFR-p75, Fas was unaltered. Perturbations of cytoskeletal elements, including tubulins, occur in diabetic neuropathy secondarily to suppressed neurotrophic support $[2,30,31]$ and are likely to impact on Golgi structure and integrity [26]. Despite the lack of mitochondrial abnormalities and evidence of apoptosis, DRG neurons demonstrated increased expression of active caspase-3, increased numbers of active caspase-3staining neurons, and upregulation of pro-apoptotic Bax, suggesting the presence of significant apoptotic stress. These findings are in agreement with those reported by Cheng and Zochodne [32] in STZ-D rats of 1-year duration. Indirect evidence for the lack of apoptotic neuronal death is the finding that neither the downstream DNA repair enzyme PARP nor cleaved PARP, as an indicator of DNA damage [32], was increased. This is in keeping with the finding that axotomy of sensory nerves of the STZ-D rats fails to induce apoptosis-related genes [33].

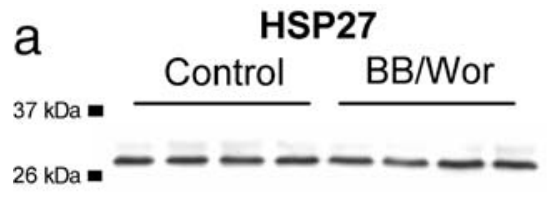

AU: $1.00 \pm 0.07 \quad 0.97 \pm 0.10$

d

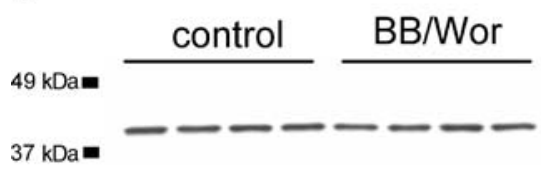

AU: $1.00 \pm 0.12 \quad 0.90 \pm 0.13$

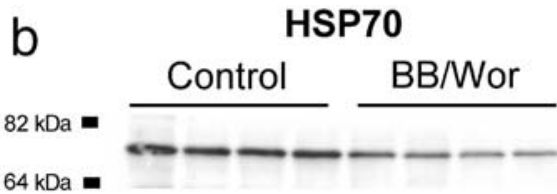

AU: $1.00 \pm 0.19$

e

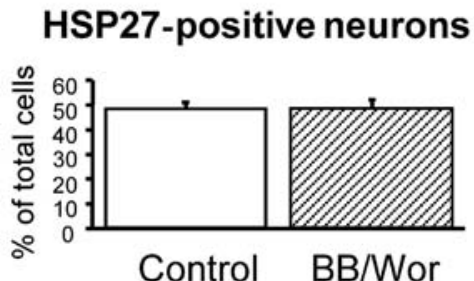

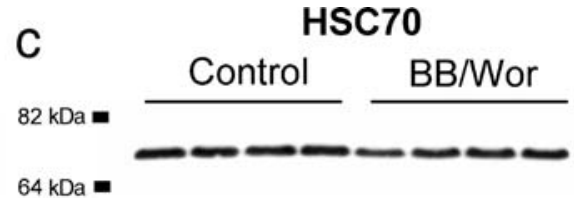

$\mathrm{AU}: 1.00 \pm 0.11$

$0.82 \pm 0.12$

Fig. 6 The levels of a HSP27; b HSP70; c HSC70; and d HSP40 in DRG (all $n=4$ ); and quantitative analyses of immunohistochemistry of DRG neurons showing e HSP27 $(n=3)$ and $\mathbf{f} \operatorname{HSP} 70(n=3)$ stainability. Results are means \pm SD. ${ }^{\mathrm{a}} p<0.05,{ }^{\mathrm{b}} p<0.005$ vs control rats 


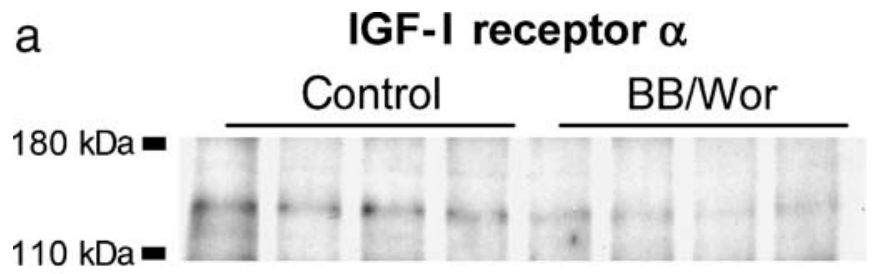

AU: $1.00 \pm 0.24$

$0.67 \pm 0.08^{a}$

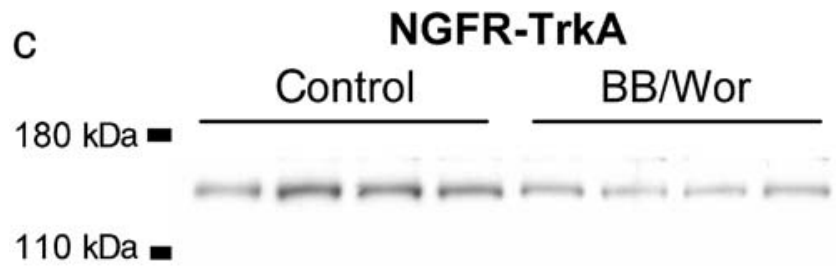

AU: $1.00 \pm 0.13$

$0.57 \pm 0.12^{c}$

Fig. 7 Concentrations of neurotrophic factors in sciatic nerve and their receptors in DRG. Levels of a IGF-I receptor in DRG $(n=4)$, b insulin receptor in DRG $(n=4)$, c NGFR-TrkA in DRG $(n=4)$, and

Taken together with the lack of structural evidence of apoptosis in this study, we speculate that apoptotic stresses do occur in long-term diabetic rats, but that these are counterbalanced by anti-apoptotic elements such as Bcl-xl, HSP27 and HSP40, which were unaltered, despite considerable neuronal loss.

HSPs have been widely investigated and their protective effect against neuronal death has been established [34-36]. HSP27 is expressed constitutively and is induced by trophic factor withdrawal or by apoptotic stress [35]. It interacts with mitochondrial cytochrome $\mathrm{c}$, blocking its interaction with Apaf-1, procaspase-9 and downstream activation of caspase-3. Caspase-12, reflective of endoplasmic reticulum dysfunction, was not altered in the present study, which is in keeping with a morphologically intact endoplasmic reticulum. As to whether apoptotic stress demonstrated here and in 4-month diabetic $\mathrm{BB} /$ Wor rats [15] may underlie the progressive degeneration of the Golgi complex remains to be investigated.

Neurotrophic support mediated by NGF, neurotrophin-3, insulin/C-peptide and IGFs have been reported to play prominent roles in the development of DPN. Withdrawal of neurotrophic support results in impaired synthesis and perturbed phosphorylation of cytoskeletal proteins, resulting in an axonal dying-back phenomenon as seen in human DPN $[1-6,17,37-40]$. This may be further perturbed through impaired sorting of proteins by the Golgi [21]. As to whether the much milder but qualitatively similar changes of neuronal Golgi complexes in aged non-diabetic rats can be related to age-related declines in neurotrophic support needs to be examined in detail.

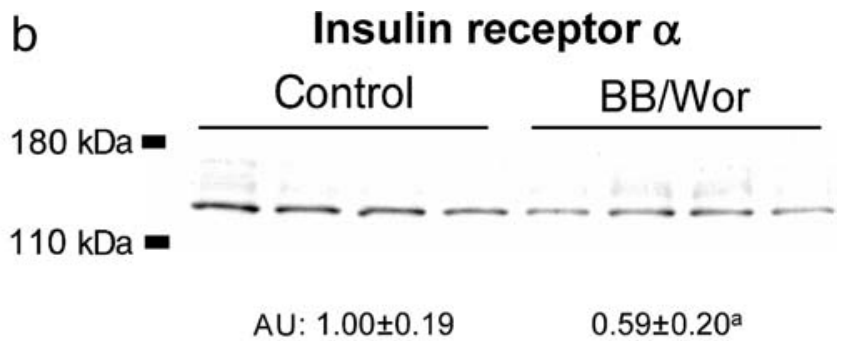

d

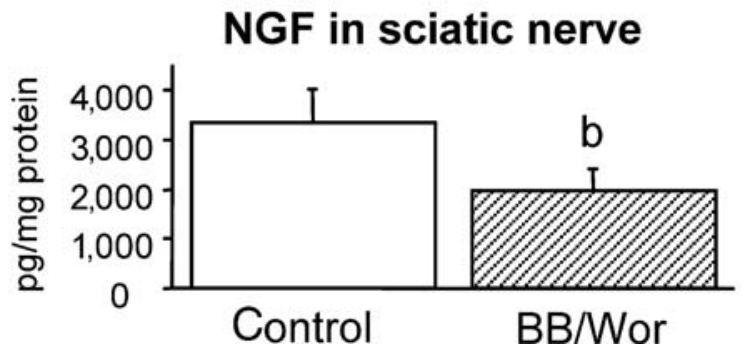

d NGF content in sciatic nerve $(n=5)$ are shown. Results are means \pm SD. ${ }^{\mathrm{a}} p<0.05,{ }^{\mathrm{b}} p<0.01,{ }^{\mathrm{c}} p<0.005$ vs control rats

We [31, 41-43] and others [6] have previously demonstrated the dependencies of neurotrophic factor synthesis and expression of their respective receptors on insulin and C-peptide signalling activity. NGF and insulin itself appear to be mainly neurotrophic to small DRG neurons $[44,45]$ and neurotrophin-3 is neurotrophic to mainly large sensory fibres [46], whereas IGF-I is more ubiquitously neurotrophic to the whole spectrum of sensory fibres [42]. It is therefore not totally surprising that small DRG neurons are particularly vulnerable to the type 1 diabetic environment as demonstrated here. This is also underscored by degeneration of C-fibres already under pre-diabetic conditions in both humans $[47,48]$ and rats [49].

The effects of neurotrophic withdrawal will impact on major cytoskeletal constituents of neuronal somata and axons, resulting in distal axonal atrophy and dying-back phenomena as shown here and previously $[1,15,17]$, and are probably responsible for atrophy of residual DRG neurons. The mechanisms by which suppressed neurotrophic support relates to the progressive degeneration of the Golgi is now being pursued in our laboratory.

In conclusion, the present study failed to convincingly demonstrate apoptotic neuronal cell death of DRG neurons in the chronically diabetic BB/Wor rat. Instead, progressive degenerative changes of the Golgi apparatus were demonstrated. Preliminary findings suggest that impaired synthesis of cytoskeletal proteins secondarily to neurotrophic suppression may underlie these degenerative changes resulting in neuronal atrophy and loss of vulnerable DRG neuronal populations. 
Acknowledgements The authors are indebted to J. Hatfield for technical assistance with the electron microscope studies. This study was supported in part by grants from the Thomas Foundation and JDRF.

Duality of interest None of the authors has any financial interest associated with this study.

\section{References}

1. Sima AAF (2003) New insights into the metabolic and molecular basis for diabetic neuropathy. Cell Mol Life Sci 60:2445-2464

2. Scott JN, Clark AW, Zochodne DW (1999) Neurofilament and tubulin gene expression in progressive experimental diabetes: failure of synthesis and export by neurons. Brain 122:2109-2117

3. Tomlinson DR, Fernyhough P (2000) Neurotrophism in diabetic neuropathy. In: Sima AAF (ed.) Frontiers in animal diabetes research. Chronic complications in diabetes. Harwood Academic, Amsterdam, pp 167-182

4. Huang TJ, Price SA, Chilton L et al (2003) Insulin prevents depolarization of the mitochondrial inner membrane in sensory neurons of type 1 diabetic rats in the presence of sustained hyperglycemia. Diabetes 52:2129-2136

5. Sayers NM, Beswick LJ, Middlemas A et al (2003) Neurotrophin-3 prevents the proximal accumulation of neurofilament proteins in sensory neurons of streptozocin-induced diabetic rats. Diabetes 52:2372-2780

6. Brussee V, Cunningham FA, Zochodne DW (2004) Direct insulin signaling of neurons reverses diabetic neuropathy. Diabetes 53:1824-1830

7. Kamiya H, Zhang W, Sima AAF (2004) C-peptide prevents nociceptive sensory neuropathy in type 1 diabetes. Ann Neurol $56: 827-835$

8. Sima AAF, Kamiya H (2004) Insulin, C-peptide and diabetic neuropathy. Sci Med 10:308-319

9. Russell JW, Sullivan KA, Windebank AJ, Herrmann DN, Feldman EL (1999) Neurons undergo apoptosis in animal and cell culture models of diabetes. Neurobiol Dis 6:347-363

10. Srinivasan S, Stevens M, Wiley JW (2000) Diabetic peripheral neuropathy: evidence for apoptosis and associated mitochondrial dysfunction. Diabetes 49:1932-1938

11. Schmeichel AM, Schmetzer JD, Low PA (2003) Oxidative injury and apoptosis of dorsal root ganglion neurons in chronic experimental diabetic neuropathy. Diabetes 52:165-171

12. Yagihashi S, Kamijo M, Ido Y, Mirrlees DJ (1990) Effects of long-term aldose reductase inhibition on development of experimental diabetic neuropathy. Ultrastructural and morphometric studies of sural nerve in streptozocin-induced diabetic rats. Diabetes 39:690-696

13. Zochodne DW, Verge VM, Cheng C, Sun H, Johnston J (2001) Does diabetes target ganglion neurones? Progressive sensory neurone involvement in long-term experimental diabetes. Brain 124:2319-2334

14. Kishi M, Tanabe J, Schmelzer JD, Low PA (2002) Morphometry of dorsal root ganglion in chronic experimental diabetic neuropathy. Diabetes 51:819-824

15. Kamiya H, Zhang W, Sima AAF (2005) Apoptotic stress is counterbalanced by survival elements preventing programmed cell death of DRGs in subacute type 1 diabetic BB/Wor-rats. Diabetes 54:3288-3295

16. Mordes JP, Bortell R, Groen H, Guberski D, Rossini AA, Greiner DL (2001) Autoimmune diabetes mellitus in the BB rat. In: Sima AAF, Shafrir E (eds) Animal models of diabetes. Harwood Academic, Amsterdam, pp 1-42
17. Sima AAF, Bouchier M, Christensen H (1983) Axonal atrophy in sensory nerves of the diabetic BB-Wistar rat, a possible early correlate of human diabetic neuropathy. Ann Neurol 13:264-272

18. Kamiya H, Zhang W, Sima AAF (2005) Unmyelinated fiber sensory neuropathy differs in type 1 and type 2 diabetes. Diabetes Metab Res Rev 21:448-458

19. Sima AAF, Ristic H, Merry A et al (1996) Primary preventive and secondary interventionary effects of acetyl-1-carnitine on diabetic neuropathy in the Bio-breeding Worcester rat. J Clin Invest 97:1900-1907

20. Sima AAF, Sugimoto K (1999) Experimental diabetic neuropathy: an update. Diabetologia 42:773-788

21. Farquhar MG, Palade GE (1998) The Golgi apparatus: 100 years of progress and controversy. Trends Cell Biol 8:2-10

22. Rios RM, Bornens M (2003) The Golgi apparatus at the cell centre. Curr Opin Cell Biol 15:60-66

23. Linstedt AD (2004) Positioning the Golgi apparatus. Cell 118:271-272

24. Ferri KF, Kroemer G (2001) Organelle-specific initiation of cell death pathways. Nat Cell Biol 3:E255-E263

25. Arvan P, Zhao X, Ramos-Castaneda J, Chang A (2002) Secretory pathway quality control operating in Golgi, plasmalemmal, and endosomal systems. Traffic 3:771-780

26. Hicks SW, Machamer CE (2005) Golgi structure in stress sensing and apoptosis. Biochim Biophys Acta 1744:406-414

27. Mancini M, Machamer CE, Roy S et al (2000) Caspase-2 is localized at the Golgi complex and cleaves golgin-160 during apoptosis. J Cell Biol 149:603-612

28. Jones SJ, Ledgerwood EC, Prins JB et al (1999) TNF recruits TRADD to the plasma membrane but not the trans-Golgi network, the principal subcellular location of TNF-R1. J Immunol 162:1042-1048

29. Bennett M, Macdonald K, Chan SW, Luzio JP, Simari R, Weissberg P (1998) Cell surface trafficking of Fas: a rapid mechanism of p53-mediated apoptosis. Science 282:290-293

30. Recio-Pinto E, Rechler MM, Ishii DN (1986) Effects of insulin, insulin-like growth factor-II, and nerve growth factor on neurite formation and survival in cultured sympathetic and sensory neurons. J Neurosci 6:1211-1219

31. Pierson CR, Zhang W, Sima AAF (2003) Proinsulin Cpeptide replacement in type 1 diabetic BB/Wor-rats prevents deficits in nerve fiber regeneration. J Neuropathol Exp Neurol 62:765-779

32. Cheng C, Zochodne DW (2003) Sensory neurons with activated caspase-3 survive long-term experimental diabetes. Diabetes 52:2363-2371

33. Burnand RC, Price SA, McElhaney M, Barker D, Tomlinson DR (2004) Expression of axotomy-inducible and apoptosis-related genes in sensory nerves of rats with experimental diabetes. Brain Res Mol Brain Res 132:235-240

34. Lewis SE, Mannion RJ, White FA et al (1999) A role for HSP27 in sensory neuron survival. J Neurosci 19:8945-8953

35. Benn SC, Perrelet D, Kato AC et al (2002) Hsp27 upregulation and phosphorylation is required for injured sensory and motor neuron survival. Neuron 36:45-56

36. Mehlen P, Schulze-Osthoff K, Arrigo AP (1996) Small stress proteins as novel regulators of apoptosis. Heat shock protein 27 blocks Fas/APO-1- and staurosporine-induced cell death. J Biol Chem 271:16510-16514

37. Greenbaum D, Richardson PC, Salmon MW, Urich H (1964) Pathologic aberrations on six cases of diabetic neuropathy. Brain $87: 201-214$

38. Sima AAF, Zhang W, Li ZG, Murakawa Y, Pierson CR (2004) Molecular alterations underlie nodal and paranodal degeneration in type 1 diabetic neuropathy and are prevented by C-peptide. Diabetes 53:1556-1563 
39. Ishii DN (1995) Implication of insulin-like growth factors in the pathogenesis of diabetic neuropathy. Brain Res Brain Res Rev 20:47-67

40. Zhuang HX, Wuarin L, Fei ZJ, Ishii DN (1997) Insulin-like growth factor (IGF) gene expression is reduced in neural tissues and liver from rats with non-insulin-dependent diabetes mellitus, and IGF treatment ameliorates diabetic neuropathy. J Pharmacol Exp Ther 283:366-374

41. Xu G, Pierson CR, Murakawa Y, Sima AAF (2002) Altered tubulin and neurofilament expression and impaired axonal growth in diabetic nerve regeneration. J Neuropathol Exp Neurol 61:164-175

42. Pierson CR, Zhang W, Murakawa Y, Sima AAF (2002) Early gene responses of trophic factors in nerve regeneration differ in experimental type 1 and type 2 diabetic polyneuropathies. J Neuropathol Exp Neurol 61:857-871

43. Li ZG, Zhang W, Sima AAF (2003) C-peptide enhances insulinmediated cell growth and protection against high glucoseinduced apoptosis in SH-SY5Y cells. Diabetes Metab Res Rev $19: 375-385$
44. Averill S, McMahon SB, Clary DO, Reichardt LF, Priestley JV (1995) Immunocytochemical localization of trkA receptors in chemically identified subgroups of adult rat sensory neurons. Eur J Neurosci 7:1484-1494

45. Sugimoto K, Murakawa Y, Sima AAF (2002) Expression and localization of insulin receptor in rat dorsal root ganglion and spinal cord. J Peripher Nerv Syst 7:44-53

46. Wright DE, Snider WD (1995) Neurotrophin receptor mRNA expression defines distinct populations of neurons in rat dorsal root ganglia. J Comp Neurol 351:329-338

47. Singleton JR, Smith AG, Bromberg MB (2001) Increased prevalence of impaired glucose tolerance in patients with painful sensory neuropathy. Diabetes Care 24:1448-1453

48. Novella SP, Inzucchi SE, Goldstein JM (2001) The frequency of undiagnosed diabetes and impaired glucose tolerance in patients with idiopathic sensory neuropathy. Muscle Nerve 24:1229-1231

49. Murakawa $Y$, Zhang W, Pierson CR et al (2002) Impaired glucose tolerance and insulinopenia in the GK-rat causes peripheral neuropathy. Diabetes Metab Res Rev 18:473-483 